\title{
SUBPROVÍNCIA DO RIO PARANÃ (GO): UM EXEMPLO DE APLICAÇÃO DOS MÉTODOS DE DATAÇÃO U-PB E PB-PB EM CASSITERITA
}

\author{
IRENA SPARRENBERGER \& COLOMBO CELSO GAETA TASSINARI
}

\begin{abstract}
PARANÃ RIVER SUBPROVINCE (GO): AN APPLICATION EXAMPLE OF THE U-Pb AND Pb-Pb CASSITERITE
DATING METHODS The Paraná Ri ver Subprovince is part of the Goiás Tin Province. It includes a basement composed mainly by orthogneisses and migmatites, named Granite-Gneiss Complex, predominantly Paleoproterozoic in age, overlaid by a metasedimentary sequence of the Ticunzal Formation, both of which were intruded by pegmatites. These units are overlain by metasedimentary and minor metavolcanic rocks of the Arai Group. Alkalic granites intrude these rocks, previously subdivided into the gl ( $\sim 1,770 \mathrm{Ma})$ and g2 ( 1,580 Ma) families, the later being responsible for the tin mineralization. Rhyolites of the Arai Group are contemporaneous to the alkaline granites. Primary tin mineralization occurs associated with the pegmatites and with late to post-magmatic alterations (greisenization, albitization) in the alkaline granites.

Coarse-grained muscovite from Xupé and Riacho dos Cavalos pegmatites yielded K-Ar ages of 2,129 \pm 26 Ma and 2,006 \pm 24 Ma, respectively. A cassiterite sample from Riacho dos Cavalos Pegmatite was analyzed by U-Pb, confirming the age between 2,023 Ma and 2,277 Ma as the time of tin mineralization. Isochronic $\mathrm{Pb}-\mathrm{Pb}$ cassiterite dating of the two pegmatites yield Archean ages, indicating that the lead incorporated by the cassiterite and its inclusions and aggregate minerais is old, probably derived from the basement. K-Ar dating of muscovite concentrates from the alkalic granites of the Mangabeira Massif yielded ages of $567 \pm 14 \mathrm{Ma}$ and $553 \pm 11 \mathrm{Ma}$, indicating overprinting of the Brasiliano Cycle in the pluton. U-Pb cassiterite dating yield na age of 1,535 $\pm 57 \mathrm{Ma}$, which is concordant with the time of crystallization of the granite and indicates that cassiterite hás not behaved as an open system in relation to the Brasiliano deformation. Isochronic Pb-Pb age of the same cassiterite sample $(1,425 \pm 79 \mathrm{Ma})$ agrees with the U-Pb age within the analytical error. From these data it is possible to identify two events of tin mineralization in the Subprovince, the oldest of Transamazonian age, represented by the pegmatites within the Granite-Gneiss Complex and the Ticunzal Formation, and the youngest of ca. 1,500 Ma, related to the $\mathbf{g} 2$ granites intrusion.
\end{abstract}

Keywords: U-Pb cassiterite dating, Goiás Tin Province, pegmatites, alkaline granites

RESUMO A Subprovíncia do Rio Paraná é parte da Província Estanífera de Goiás e inclui um embasamento predominantemente ortognáissico e migmatítico de idade Transamazônica (Complexo Granito-Gnáissico), superposto por rochas metassedimentares da Formacão Ticunzal, ambos intrudidos por pegmatitos e sotopostas às rochas metassedimentares, subordinadamente metavulcânicas, do Grupo Arai. Granitos alcalinos intrudem estas rochas e foram previamente subdivididos em duas famílias, g 1 ( $-1.770 \mathrm{Ma})$ e g2 (-1.580 Ma), a última responsável pela mineralização estanífera. São contemporâneos aos metamólitos do Grupo Arai. A mineralização estanífera primária está associada aos pegmatitos dos Complexo Granito-Gnáissico e da Formação Ticunzal, bem como a alterações tardi- a pós-magmáticas (greisenização, albitização) nos granitos alcalinos.

Muscovita grossa dos pegmatitos Xupé e Riacho dos Cavalos forneceu idades K-Ar de 2.129 26 Ma e $2.006 \pm 24$ Ma, respectivamente. Uma amostra de cassiterita do Pegmatito Riacho dos Cavalos forneceu uma idade U-Pb que confirma o período entre $2.023 \mathrm{Ma}$ e $2.277 \mathrm{Ma}$ como a época da mineralização estanífera. Isócronas $\mathrm{Pb}-\mathrm{Pb}$ de cassiterita dos dois pegmatitos forneceram idades arqueanas, sugerindo que o chumbo incorporado pela muscovita e suas inclusões e minerais agregados é antigo, derivado provavelmente do embasamento. Datações K-Ar de dois concentrados de muscovita do Granito Mangabeira forneceram idades de $567 \pm 14$ Ma e $553 \pm 11$ Ma, indicando influência do Ciclo Brasiliano sobre o maciço. Datação U-Pb de cassiterita revelou uma idade de $1.535 \pm 57 \mathrm{Ma}$, coerente com a da cristalização do granito, indicando que a cassiterita não se comportou como sistema aberto durante a deformação brasiliana. A idade isocrônica Pb-Pb dessa cassiterita (1 .425 \pm 79 Ma) é concordante, dentro do erro analítico, com a sua idade U-Pb. Esses dados permitem concluir que a mineralização estanífera ocorreu em pelo menos dois eventos, um de idade transamazônica, representado pelos pegmatitos do Complexo Granito-Gnáissico e da Formação Ticunzal, e outro, em ca. de 1.500 Ma, relacionado à intrusão dos granitos da família $\mathbf{g} 2$.

Palavras-chave: datação U-Pb em cassiterita, Província Estanífera de Goiás, pegmatitos, granitos alcalinos

INTRODUÇÃO As análises isotópicas em mineralizações são importantes para determinações de idades e para o estabelecimento de modelos conceituais de depósitos minerais, bem como para a definição de províncias metalogenéticas e caracterização das fontes dos fluidos mineralizantes. Normalmente, essas análises são feitas indiretamente, ou seja, utilizam-se minerais de ganga associados ou de alteração hidrotermal, e rochas alteradas hidrotermalmente. Mais recentemente, tem-se procurado aplicar análises isotópicas diretamente nos minerais de minério (e.g., Ludwig \& Cooper 1984, Corfu \& Andrews 1986 , Schärer et al 1986, Richards et al. 1988, Turpin et al 1988, Bell et al 1989, Corfu \& Muir 1989, Mezger et al. 1989, Bjorlykke et al 1990, Schandl et al. 1990, Gulson \& Jones 1992, Romer \& Wright 1992, Romer \& Smeds 1994, Romer \& Lehmann 1995, Darbyshire et al. 1996, Frei \& Pettke 1996, Romer \& Smeds 1997), o que confere uma maior confiabilidade em que os resultados obtidos representem realmente as mineralizações.

Seguindo essa tendência, este trabalho apresenta determinações isotópicas $\mathrm{Pb}-\mathrm{Pb}$ e U-Pb em cassiterita da Subprovíncia Paraná, integrante da Província Estanífera de Goiás definida por Marini \& Botelho (1986), utilizando as técnicas analíticas apresentadas por Gulson \& Jones (1992) para datações de cassiterita dos depósitos estaníferos do Complexo Bushveld, arqueano, e da ilha de Belitung, na Indonésia, com idade aproximada de $200 \mathrm{Ma}$.

O significado geológico das datações efetuadas neste trabalho foi controlado por datações K-Ar em muscovita proveniente das mineralizações estudadas e dos dados geocronológicos regionais pré-existentes. Além disso, a qualidade dos dados obtidos e a aplicabilidade da técnica foram discutidos com base na caracterização da cassiterita por microscopia eletrônica de varredura (MEV).

A partir dos dados obtidos, definiu-se a idade de pelo menos dois eventos responsáveis pelas mineralizações na Subprovíncia do Rio
Paraná, Província Estanífera de Goiás. Com base em diagramas isocrônicos $\mathrm{Pb}-\mathrm{Pb}$ dos concentrados de cassiterita, foi inferida a presença de um embasamento antigo na porção nordeste da Subprovíncia. A cronologia dos diversos eventos mineralizantes representados na área foi, até o momento, acessada apenas indiretamente, no caso das ocorrências relacionadas aos granitos, por datações pelos métodos Rb-Sremrochatotal(e.g.,Hasuiefa/. 1980,Tassinariefa/. 1981,Reis Neto 1983, Marini et al. 1985) e U-Pb em zircão (e.g., Pimentel et al. 1991). Para as ocorrências relacionadas aos exogreisens e aos pegmatitos não existem determinações geocronológicas disponíveis na literatura até o momento.

GEOLOGIA REGIONAL As rochas do embasamento da Subprovíncia do Rio Paranã (Fig. 1) são de natureza essencialmente ortognáissica e migmatítica, e pertencem ao denominado Complexo Granito-Gnáissico (Marini et al. 1984). Segundo Fuck et al. (1987), a unidade constitui um domínio transamazônico, com idades entre 1.750 e $2.000 \mathrm{Ma}$, que contém núcleos arqueanos preservados. Botelho (1992a) subdividiu as rochas desse complexo no setor central da Subprovíncia em quartzo-dioritos e granodioritos (GRÃ) e granitos cinzas (GRB), ambos pertencentes à mesma série magmática cálcioalcalina. Os granitos GRÃ, aflorantes a sul e a leste do Maciço da Pedra Branca e nas imediações de Nova Roma, seriam precoces. Os granitos GRB ocupam o restante do setor central da Subprovíncia, sendo tardios.

Recobrindo discordantemente o Complexo Granito-Gnáissico, ocorrem xistos e gnaisses frequentemente grafitosos, de fácies anfibolito, identificados por Marini et al. (1978) e denominados Formação Ticunzal por Fernandes et al. (1982).

Os pegmatitos estaníferos aflorantes a nordeste de Monte Alegre de Goiás são intrusivos tanto no Complexo Granito-Gnáissico como nos metassedimentos da Formação Ticunzal. Caracterizam-se por

* Centro de Pesquisas Geocronológicas (CPGeo), Instituto de Geociências, Universidade de São Paulo, Caixa Postal 11348, CEP 05422-970, São Paulo - SP

e-maii. sparrenb@usp.brou ccgtassi@usp.br 


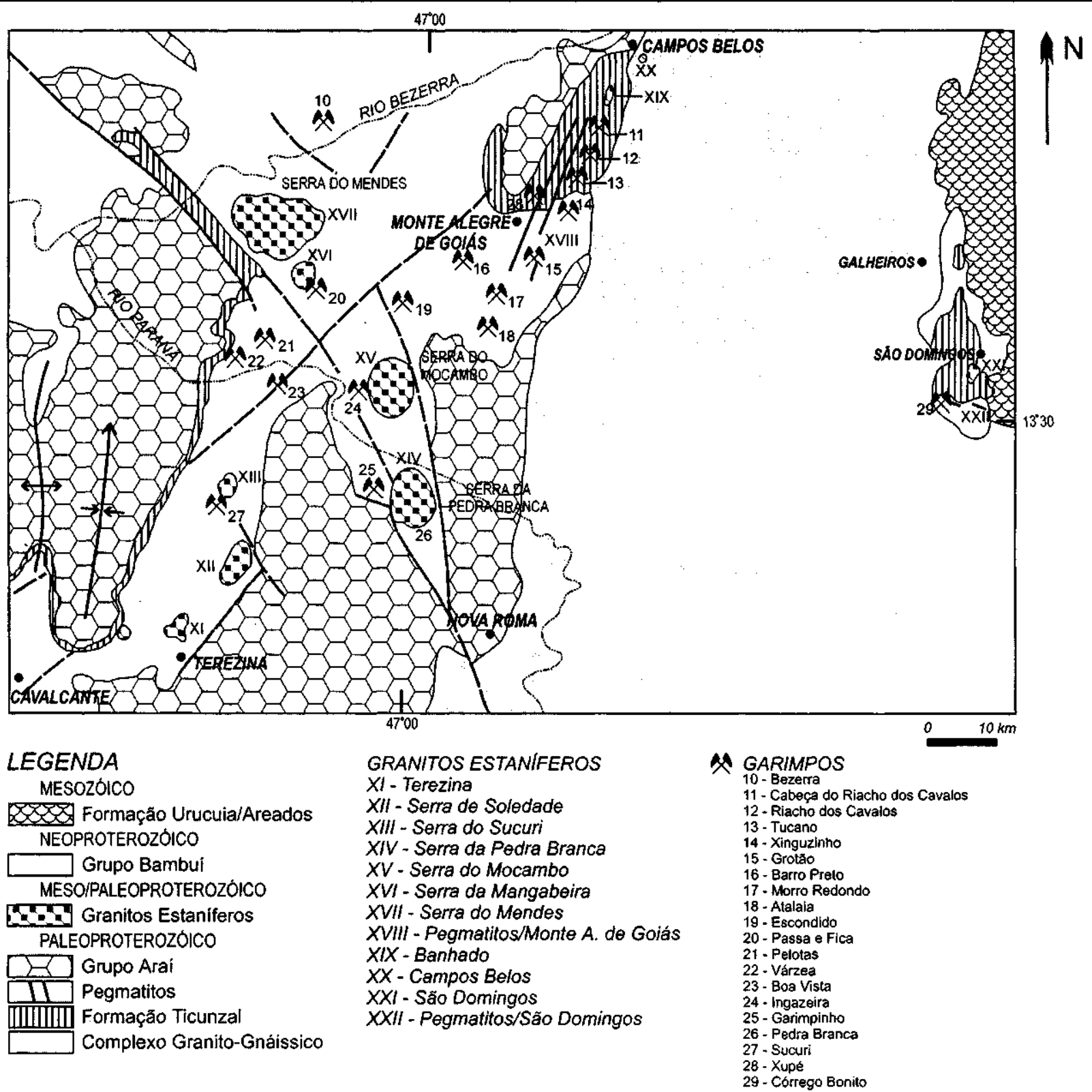

Figura l- Mapa geológico da Subprovíncia do Rio Paraná, integrante da Província Estanífera de Goiás. (Modificado de Marini \& Botelho 1986).

corpos aplítico-pegmatíticos ou de greisens descontínuos, condicionados por uma zona de cisalhamento regional de direção N-NE (Montanheiro 1994). Esses pegmatitos são mineralizados também com Ta-Nb, quartzo, mica e caulim (Pagotto \& Kenji, in Botelho et al. 1986).

O Grupo Arai (Dyer 1970), que compreende as formações Arraias, na base, e Traíras, no topo, também repousa discordantemente sobre o Complexo Granito-Gnáissico. A Formação Arraias é constituída por metassedimentos elásticos finos, quartzitos, metaconglomerados e meta vulcânicas básicas até ácidas. A Formação Traíras é composta por metassedimentos elásticos finos e quartzitos, todos metamorfizados em fácies xisto verde. Pimentel et al. (1991) dataram por U-Pb duas frações de zircão dos metarriólitos do Grupo Arai, obtendo uma idade de $1.771 \pm 2 \mathrm{Ma}$, que caracteriza a deposição desta unidade como paleoproterozóica.

Contemporâneos ao Grupo Arai, conforme sugerem as datações U-Pb em zircão de Pimentel et al. (1991), os granitos estaníferos da Subprovíncia do Rio Paraná (tipo Serra Branca, Fernandes et al. 1982) intrudem o Complexo Granito-Gnáissico e a Formação Ticunzal. Compreendem corpos circulares com orientação mineral difusa, pre- dominantemente porfiríticos, de biotita, muscovita ou biotitamuscovita granitos. Do ponto de vista geoquímico, são ricos em $\mathrm{SiO}_{2}$, peraluminosos, cálcio-alcalinos e alcalinos (Marini \& Botelho 1986). Botelho (1992a, b, 1997) separou esses corpos nas famílias magmáticas g1 e g2, sendo a primeira mais comum e mais antiga (1.770 Ma), e a $\mathbf{g 2}$, responsável pela mineralização, de ocorrência restrita principalmente aos maciços Pedra Branca e Mangabeira, mais jovem (1.580 Ma). Os granitos de ambas as famílias possuem características de granitos do tipo A, sendo os gl alcalinos e os $\mathbf{g 2}$ metaluminosos a peraluminosos. A mineralização estanífera está relacionada a alterações tardi- a pós-magmáticas (albitização, greisenização) desses granitos.

No extremo leste da Subprovíncia do Rio Paranã ocorrem rochas pertencentes ao Subgrupo Paraopebas do Grupo Bambuí, cuja génese e deformação estão relacionadas ao Ciclo Brasiliano.

A Subprovíncia do Rio Paranã apresenta mineralização primária de cassiterita associada a albititos no Granito Sucuri, endogreisens de fratura e de cúpula nos granitos Mangabeira e Pedra Branca, exogreisens de fratura encaixados no Complexo Granito-Gnáissico junto às bordas dos granitos Pedra Branca e Mocambo, e a pegmatitos situados 

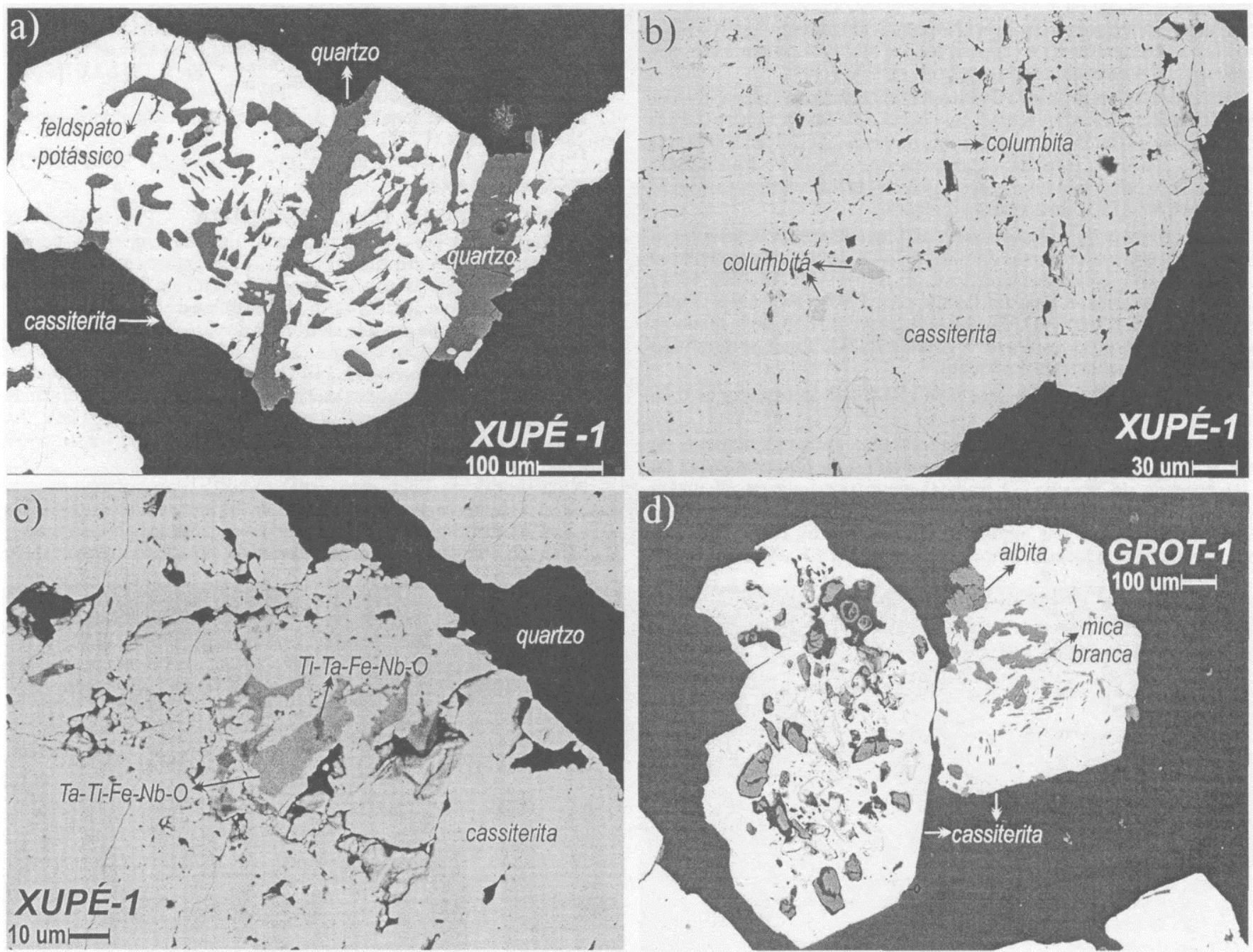

Figura 2 - Imagens de microscópio eletrônico de varredura de a) cristal de cassiterita da amostra XUPE-1 com abundantes inclusões de feldspato potássico, cortado por venulações de quartzo; b) cristal de cassiterita da amostra XUPÉ-1 com exsoluções e micro-inclusões de columbita-tantalita; c) cassiterita da amostra XUPE-1 cortada por venulação de quartzo e com exsoluções de rutilo com teores variáveis de Ta (strüverita); d) dois grãos de cassiterita da amostra GROT-1 com numerosas inclusões de albita alojadas em vacúolos e de mica branca.

na região do município de Monte Alegre de Goiás (Botelho et al. 1986) (Fig. 1).

PROCEDIMENTOS ANALÍTICOS Para um maior controle sobre o significado geológico das idades obtidas pelos métodos U-Pb $\mathrm{e} \mathrm{Pb}-\mathrm{Pb}$ em cassiterita, foram também realizadas análises pelo método $\mathrm{K}-\mathrm{Ar}$ em concentrados de muscovita provenientes dos pegmatitos Xupé e Riacho dos Cavalos e do Granito Mangabeira. Os concentrados foram obtidos segundo os métodos convencionais utilizados no Centro de Pesquisas Geocronológicas (CPGeo) do Instituto de Geociências da Universidade de São Paulo, que envolveram a britagem, peneiramento e purificação dos concentrados via separação magnética em Separador Isodinẩmico tipo Frantz. Os procedimentos analíticos para a extração do $\mathrm{K}$ e do Ar encontram-se descritos em Torquato \& Kawashita(1992).

A cassiterita submetida à datação U-Pb foi obtida a partir de concentrados de bateia, no caso das amostras XUPÉ-1, GROT-1 e INGA-2, e de rochas para as amostras GROT-2, RC-5 e PF-7. As amostras de rocha foram britadas em britador de mandíbulas e então peneiradas, assim como os concentrados de bateia, nos intervalos granulométricos $>35 \#, 35-60 \#, 60-100 \#, 100-150 \#$ e $<150 \#$. Tais frações foram submetidas à separação por líquidos densos, empregando-se o bromofórmio $\left(\mathrm{d}=2,8899 \mathrm{~g} / \mathrm{cm}^{3}\right)$ e o iodeto de metileno $\left(\mathrm{d}=3,325 \mathrm{~g} / \mathrm{cm}^{3}\right)$, sendo apenas as três fraçoes mais grossas utilizadas para datação. A seleção dos cristais de cassiterita foi efetuada com auxílio de lupa binocular.

Os procedimentos analíticos basearam-se nos sugeridos por Gulson \& Jones (1992), com algumas modificações. Inicialmente, foi reali- zada lavagem dos grãos selecionados com uma mistura de $\mathrm{HNO}_{3} 8 \mathrm{~N}$ e $\mathrm{HC} 16 \mathrm{~N}$ em ultra-som, por 30 minutos, visando à eliminação dos traços de sulfetos e remoção do $\mathrm{Pb}$ comum. A seguir, os concentrados foram reduzidos à granulação inferior a $140 \# \mathrm{com}$ almofariz e pistilo de ágata, empregando-se malhas de nylon no seu peneiramento. Os materiais resultantes foram novamente submetidos à separação gravimétrica com iodeto de metileno, com o objetivo de minimizar o volume de inclusões e minerais agregados liberados pela moagem. Separação magnética com aparelho tipo Frantz foi efetuada apenas na fração INGA-2 60-100\#, empregando-se inclinações frontal e lateral de $20^{\circ}$ e $1,0 \mathrm{~A}$ de corrente elétrica.

As amostras, com pesos entre 90 e $205 \mathrm{mg}$, foram então acondicionadas em bomba tipo Parr de $23 \mathrm{~mL}$ para dissolução, à qual adicionaram-se $2 \mathrm{~mL}$ de $\mathrm{HC} 110 \mathrm{~N}$ para cada $50 \mathrm{mg}$ de pó de cassiterita. A mistura foi aquecida em estufa à $200^{\circ} \mathrm{C}$ por um tempo mínimo de quatro dias. Após a dissolução total, as soluções foram subdivididas nas alíquotas para análise por diluição isotópica (DI), que constituiu $1 / 3$ do volume total, e análise da composição isotópica $(\mathbf{C I})$, que compreendeu os $2 / 3$ restantes. À primeira alíquota adicionaram-se duas gotas de solução traçadora (spike) $\mathrm{de}^{208} \mathrm{~Pb} /{ }^{235} \mathrm{U}$. As soluções foram aquecidas à secura e condicionadas em $1 \mathrm{~mL}$ de $\mathrm{HC} 18,3 \mathrm{~N}$.

Para a extração do U e do $\mathrm{Pb}$ empregaram-se, inicialmente, colunas de polietileno convencionais com $0,5 \mathrm{~mL}$ de resina AG1-X8 (200$400 \#$ ) na forma clorídrica, condicionadas com HC1 8,3N. As amostras foram passadas duas vezes nessa coluna, tendo sido a solução inteiramente coletada nas alíquotas CI e DI destinada à análise de Pb. O U foi extraído da fração DI em béquer (savillex) separado, mediante a 
adição de $2 \mathrm{~mL}$ de $\mathrm{HC} 11$,6N, por duas vezes, à coluna. As soluções resultantes foram aquecidas à secura e condicionadas em $1 \mathrm{~mL}$ de $\mathrm{HBr}$, no caso das alíquotas CI e DI para análise de $\mathrm{Pb}$. A alíquota Dl para análise de $\mathrm{U}$ foi condicionada em $2 \mathrm{~mL}$ de $\mathrm{HNO}_{3} 8 \mathrm{~N}$.

Procedeu-se à purificação do $\mathrm{Pb}$ em minicolunas de TeflonSINALMARCAREGISTRADA retrátil com cerca de $9 \mathrm{~cm}$ de altura e $0,8 \mathrm{~cm}$ de diâmetro, preenchidas com $0,1 \mathrm{~mL}$ de resina AG1-X8 (200-400\#) na forma clorídrica e condicionadas em $\mathrm{HBr} \mathrm{IN}$. $\mathrm{O} \mathrm{Pb}$ foi coletado com $\mathrm{HCl} 6 \mathrm{~N}$, adicionando-se então 1 gota de $\mathrm{HsPO}_{4}$ super puro diluído 20 vezes à solução e aquecendo-a à secura.

A purificação do $U$ baseou-se nos procedimentos descritos em Babinski (1993), e consistiu da utilização de colunas de polietileno convencionais preenchidas com $2 \mathrm{~mL}$ de resina AG1-X8 (200-400\#) na forma clorídrica, a qual foi lavada com $\mathrm{H}_{2} \mathrm{O}$ e HCI $6 \mathrm{~N}$ e condicionada com $\mathrm{HNOs} 8 \mathrm{~N}$. O U foi coletado com $\mathrm{H}_{2} \mathrm{O}$ e $\mathrm{HCI} 6 \mathrm{~N}$, tendo-se adicionado à solução resultante 1 gota de $\mathrm{HsPO} 4$ super puro diluído 20 vezes, e foi aquecida até a secura.

O branco analítico de $\mathrm{Pb}$ para cada $150 \mathrm{mg}$ de amostra foi de 0,46 ng-

As análises isotópicas foram processadas em espectrômetro de massa Finnigan, modelo 262, no Laboratório de Geocronologia da Universidade de Brasília. O fracionamento por unidade de massa atómica aferido com padrões NBS SRM 981 e 982 está entre 0,12 e $0,14 \%$. A deposição das amostras no filamento de Rênio seguiu o procedimento padrão, com emprego de sílica gel e $\mathrm{H}_{3} \mathrm{PO}_{4}$. $\mathrm{O}$ isótopo
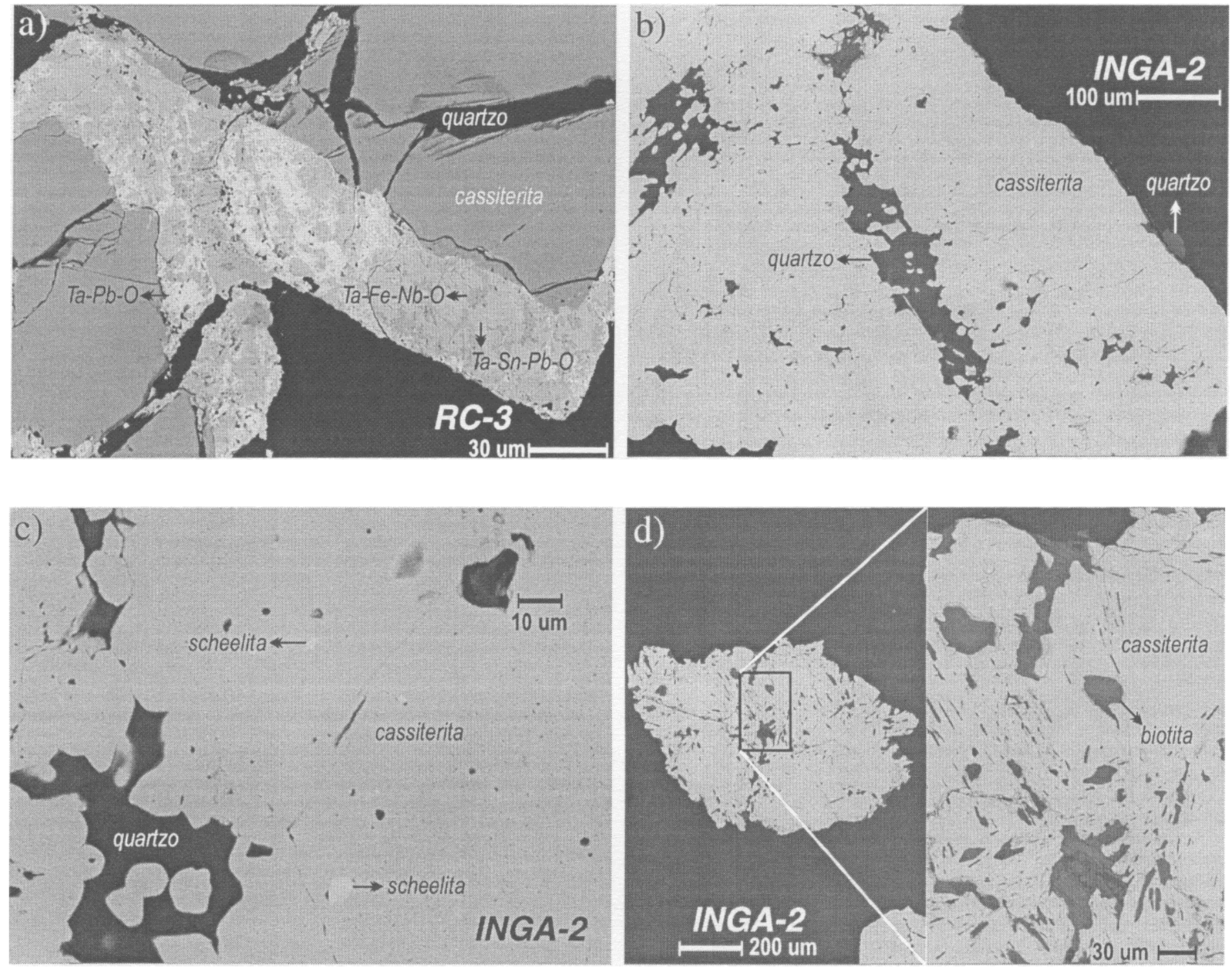

Figura 3 - Imagens de microscópio eletronico de varredura de a) cassiterita da amostra RC-3 isenta de inclusões, mostrando fraturaspreenchidas por óxidos da série da tapiolita e do subgrupo da microlita, à base de Ta, Fe e Nb, no primeiro caso, e Ta e Pb, com ou sem Sn, no caso da microlita; b) cristal de cassiterita da amostra INGA-2 com segregações de quartzo que englobam fragmentos da cassiterita, indicando cataclase; c) detalhe do cristal da figura $3 b$ mostrando diminutas inclusões arredondadas ou elipsoidais de scheelita; d) cassiterita da amostra INGA-2, mostrado em detalhe à direita da figura, que exibe numerosas inclusões de biotita. 
Tabela l- Dados analíticos K-Ar de concentrados de muscovita da Subprovíncia do Rio Paraná (GO).

\begin{tabular}{|c|c|c|c|c|c|c|c|c|}
\hline $\begin{array}{l}\mathrm{n}^{\mathrm{g}} \mathrm{de} \\
\text { lab. }\end{array}$ & $\begin{array}{c}\mathrm{n}^{\mathrm{O}} \mathrm{de} \\
\text { campo }\end{array}$ & rocha & material & $\% \mathrm{~K}$ & $\begin{array}{c}{ }^{40} \mathrm{Ar} \mathrm{rad} \\
\left(\operatorname{ccSTP} / \mathrm{g} \times 10^{-6}\right)\end{array}$ & $\begin{array}{c}\text { Ar atm. } \\
(\%)\end{array}$ & $\begin{array}{l}\text { idade } \\
\text { (Ma) }\end{array}$ & $\begin{array}{c}\text { erro } \\
\text { (Ma e \%) }\end{array}$ \\
\hline 7476 & FXS5-3 & $\begin{array}{l}\text { grano- } \\
\text { diorito }\end{array}$ & muscovita & 7,84 & 985,51 & 0,52 & 1.855 & $40(2,2 \%)$ \\
\hline 7477 & XUPÉ-3 & greisen & muscovita & 7,04 & 1112,64 & 2,65 & 2.129 & $26(1,2 \%)$ \\
\hline 7478 & FGS5-3 & $\begin{array}{l}\text { grano- } \\
\text { diorito }\end{array}$ & muscovita & 8,60 & 1022,91 & 0,38 & 1.790 & $23(1,3 \%)$ \\
\hline 7480 & $\begin{array}{c}\text { FAS18- } \\
2 \\
\end{array}$ & $\begin{array}{l}\text { monzo- } \\
\text { granito }\end{array}$ & muscovita & 8,46 & 1187,64 & 0,62 & 1.984 & $26(1,3 \%)$ \\
\hline 7479 & $\mathrm{RC}-5$ & greisen & muscovita & 7,81 & 1116,58 & 0,49 & 2.006 & $24(1,2 \%)$ \\
\hline 7472 & PF-2 & $\begin{array}{l}\text { leuco- } \\
\text { granito }\end{array}$ & muscovita & 7,97 & 206,31 & 1,31 & 567 & $14(2,4 \%)$ \\
\hline 7473 & PF-7 & $\begin{array}{l}\text { leuco- } \\
\text { granito }\end{array}$ & muscovita & 8,11 & 203,87 & 1,25 & 553 & $11(2,0 \%)$ \\
\hline
\end{tabular}

microscópio eletrônico de varredura, observa-se que os cristais exibem fraturas, via de regra preenchidas por feldspato ou quartzo (Figs. 2a e 2c). Alguns grãos apresentam abundantes inclusões unicamente de feldspato potássico, com dimensões da ordem de 20 a 130 um (Fig. $2 \mathrm{a})$, enquanto que outros contêm micro-inclusões e exsoluções de columbita-tantalita (Fig. 2b) e rutilo (com teores variáveis de tântalo) de até $40 \mu \mathrm{m}$ (Fig. 2c).

No caso do Pegmatito Grotão, obtiveram-se as amostras GROT-1, a partir da purificação de concentrado de bateia, e GROT-2, proveniente de amostra de rocha. A caracterização da cassiterita desse depósito foi baseada em análises de GROT-1, sendo castanho-escura, opaca a translúcida, e exibindo brilho graxo a adamantino. Seus cristais são predominantemente subédricos, de hábito bipiramidal, e contêm volume significativo de silicatos (quartzo, mica branca) aderidos à sua superficie. As imagens de microscópio eletrônico de varredura revelaram a presença abundante de inclusões de mica branca e de albita, a última comumente alojada em vacúolos de 10 a $150 \mu \mathrm{m}$ de dimensão (Fig. 2d). Alternativamente, outros cristais apresentam raras inclusões ou cristais agregados exclusivamente de columbita-tantalita, que atingem desde 20 até 130 um.

A cassiterita do Pegmatito Riacho dos Cavalos foi caracterizada a partir de grãos selecionados do concentrado de bateia (amostra RC-3), ao passo que a amostra submetida à datação (RC-5) é proveniente de exemplar de greisen grosso, composto por muscovita, quartzo, cassiterita e columbita-tantalita. Apresenta cor castanho-escura, é opaca, e exibe brilho submetálico a adamantino. Seu hábito é subédrico, bipiramidal. As imagens de microscópio eletrônico de varredura revelaram que os cristais são desprovidos de inclusões, cortados apenas por fraturas preenchidas com quartzo. Fases tardias complexas, no entanto, ocorrem agregadas à superficie dos grãos ou preenchendo microvenulações. Tratam-se de óxidos de tântalo intercrescidos, cuja composição química é compatível com minerais da série da tapiolita e do subgrupo da microlita, grupo do pirocloro, mais especificamente microlita com chumbo e microlita com estanho (Fig. 3a).

A cassiterita da amostra INGA-2 (depósito Ingazeira) é castanhomédia até escura, opaca a translúcida, e apresenta brilho submetálico a graxo. Predominam cristais de hábito subédrico, tendendo a anédrico. Ao microscópico eletrônico de varredura, observam-se texturas sugestivas de cataclase incipiente sobre a cassiterita, tais como fraturas preenchidas por quartzo que engloba fragmentos do mineral hospedeiro (Figs. 3b e 3c).

No que diz respeito a inclusões, a cassiterita da Ingazeira contém raros e diminutos cristais anédricos de scheelita, de formas elipsoidais ou arredondadas e até $10 \mu \mathrm{m}$ de dimensão (Fig. 3b), e abundantes cristais de biotita com cerca de 5 a $130 \mu \mathrm{m}$ (Fig. 3d).

A última amostra caracterizada foi PF-7, proveniente do Granito Mangabeira. Sua cassiterita é castanho-escura, opaca a localmente translúcida, onde assume cor avermelhada. Apresenta brilho adamantino e hábito subédrico a anédrico. Em virtude do pequeno volume de amostra disponível, não foi possível analisá-la ao microscópio eletrônico de varredura.
RESULTADOS GEOCRONOLÓGICOS E DISCUSSÕES Método K-Ar Por meio do método K-Ar obtiveram-se três datações em muscovita de monzogranitos e granodioritos variavelmente deformados sob condições de fácies xisto verde, que constituem as rochas encaixantes dos pegmatitos Xupé, Grotão e Riacho dos Cavalos. Foram obtidas, respectivamente, as idades de $1.855 \pm 40$, $1.790 \pm 23$ e $1.984 \pm 26 \mathrm{Ma}$ (Tabela 1). Tais dados são interpretados como idades mínimas ou de resfriamento do evento metamórfico que afetou a área, relacionado à zona de cisalhamento N-NE na qual os referidos pegmatitos se alojaram.

Amostras de greisens grossos a muito grossos compostos por moscovita verde-clara, quartzo, cassiterita e columbita-tantalita, representativas de variações faciológicas dos pegmatitos Xupé e Riacho dos Cavalos, forneceram idades K-Ar em muscovita de $2.129 \pm 26$ e $2.006 \pm 24 \mathrm{Ma}$ (Tabela 1), respectivamente. Esses valores são considerados como a época de fechamento do sistema $\mathrm{K}$-Ar na mica $\left(350^{\circ} \pm 50^{\circ} \mathrm{C}\right.$, Hanes 1991$)$ durante a cristalização dos pegmatitos, haja vista a granulação grossa da fase mineral, que tende a dificultar a difusão e perda de Ar através do retículo cristalino, e a ausência de texturas que indiquem deformação da rocha. Neste contexto, podemos considerar o Complexo Granito-Gnáissico e a Formação Ticunzal mais antigos do que $2.150 \mathrm{Ma}$, uma vez que são intrudidos pelos pegmatitos datados. Logo, as idades $\mathrm{K}$-Ar entre $1,98 \mathrm{Ga}$ e $1,79 \mathrm{Ga}$, realmente representam idades mínimas daquelas rochas, que teriam sofrido perda total ou parcial de Ar radiogênico durante o evento deformacional que as afetou.

Com relação aos granitos alcalinos, foram realizadas duas análises $\mathrm{K}$-Ar em muscovita de leucogranitos do maciço Mangabeira coletados na chamada apófise, localizada a sudoeste da intrusão principal. Essas rochas são compostas por microclínio, quartzo, albita e mica verdeclara, e apresentam estrutura xistosa. As idades obtidas foram de $567 \pm 14$ Ma e $553 \pm 11$ Ma, refletindo a orogênese brasiliana sobre as mesmas.

Métodos U-Pb e Pb-Pb Os dados obtidos por meio das análises isotópicas $\mathrm{U}-\mathrm{Pb}$ e $\mathrm{Pb}-\mathrm{Pb}$ na cassiterita estão resumidos na Tabela 2 , tendo sido calculados e plotados com auxílio dos programas PBDAT versão 1.24 (Ludwig 1993) e ISOPLOT versão 2.70 (Ludwig 1993). Considerando-se os granitos alcalinos, a análise de uma fração de cassiterita do maciço Mangabeira (PF-7 35-60\#) constatou teor de U de 324,76 ppm que pode ser considerado anómalo em comparação àqueles citados na literatura (e.g., Berzina \& Dolomanova 1967, Swart \& Moore 1982, Zagruzina et al. 1987, Gulson \& Jones 1992), que situam-se no intervalo de 0,00 e $21,00 \mathrm{ppm}$. O ponto analítico relativo a essa amostra, quando plotado em diagrama $\mathrm{U}-\mathrm{Pb}$, é bastante concordante, situando-se próximo a curva Concórdia e fornecendo uma idade mínima de $1.470 \pm 24 \mathrm{Ma}$ forçando-se a regressão linear a zero, e empregando-se correção do $\mathrm{Pb}$ comum inicial segundo Stacey \& Kramers (1975) de $1.600 \mathrm{Ma}$ (Fig. 4a). Entretanto, como a atuação da Orogênese Brasiliana sobre o maciço foi constatada pelas análises pelo método K-Ar em mica branca a idade de $560 \mathrm{Ma}$ foi utilizada como intercepto inferior para outra regressão (Fig. 4b), sendo obtida a idade 

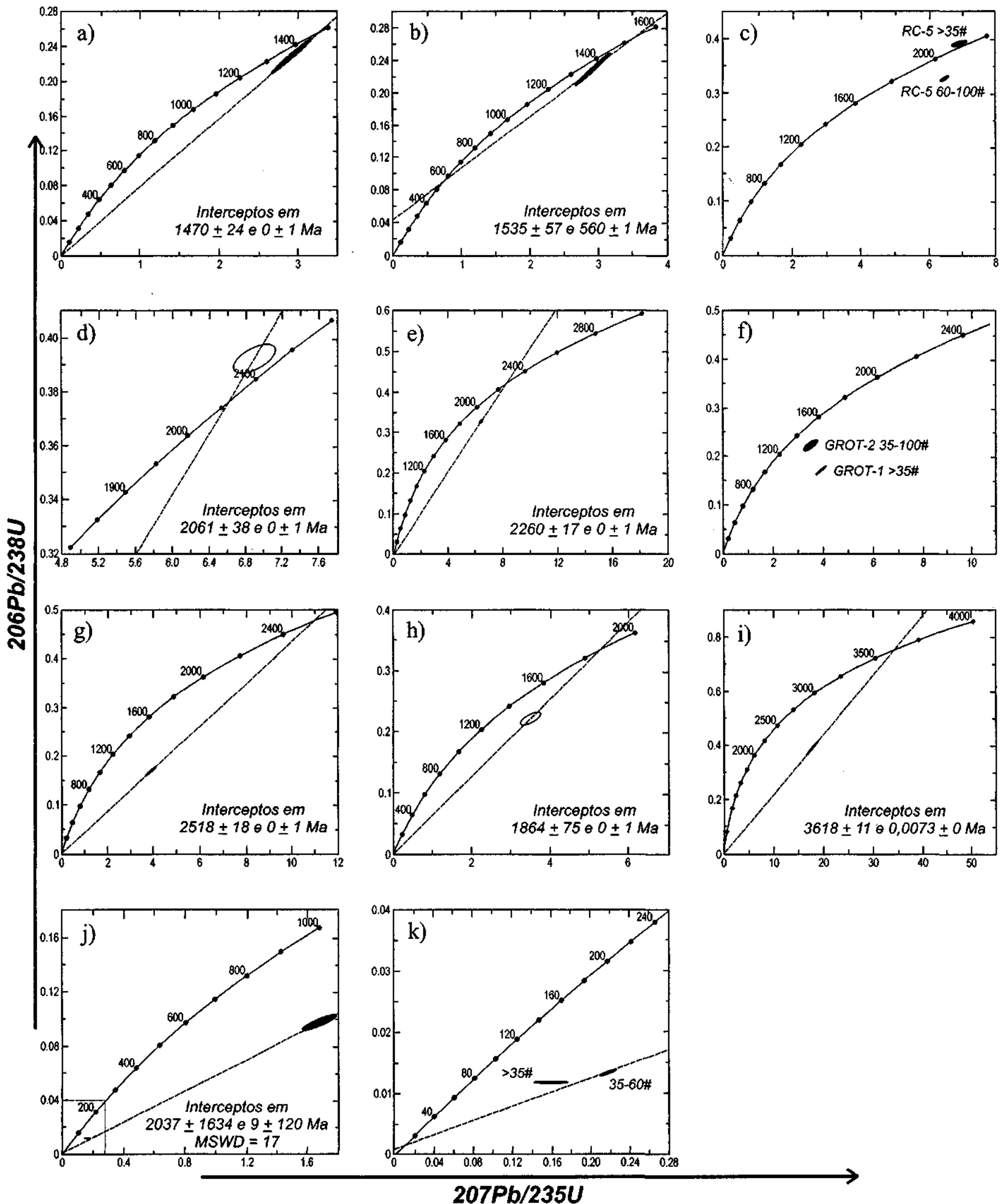

Figura 4 - Diagramas Concórdia dafração PF-7 35-60\#, com a) intercepto inferior igual a zero, e b) intercepto inferior igual à média das duas datações K-Ar em muscovita do Granito Mangabeira (560 Ma); c) dasfrações RC-5 >35\# e 60-100\#; das regressões a intercepto inferior igual a zero dasfrações d) RC-5 >35\# e) RC-5 60-100\#, separadamente; f) dasfrações GROT-1 >35\# e GROT-2 35-100\#; das regressões a intercepto inferior igual a zero dasfrações g) GROT-1 >35\# e h) GROT-2 35-100\#, separadamente; i) dafração XUPÉ-1 60-100\#; j) dasfrações >35\#, 35-60\# e 60-100\# não magnética da amostra INGA-2, cujo quadro em destaque encontra-se ampliado em $k$ ). 
de $1.535 \pm 57 \mathrm{Ma}$, que é coerente, dentro dos erros analíticos, com a idade convencional $\mathrm{Rb}-\mathrm{Sr}$ determinada por Hasui et al. (1980) para a cristalização do Granito Mangabeira, de $1.574 \pm 47$ Ma. Esses dados sugerem que a mineralização ocorreu nos estágios finais de desenvolvimento do corpo granítico, relacionada aos eventos tardi-magmáticos associados a evolução do maciço.

Quanto aos pegmatitos de Monte Alegre de Goiás, duas frações granulométricas de cassiterita extraídas da mesma amostra de greisen grosso do Pegmatito Riacho dos Cavalos foram também analisadas pelo método U-Pb. Apesar de seguramente pertencerem à mesma geração, seus pontos analíticos, quando plotados no diagrama Concórdia, não se alinham (Fig. 4c), o que pode ter explicação na presença de óxidos de $\mathrm{Ta} \mathrm{e} \mathrm{Pb}$, com ou sem $\mathrm{Sn}$, agregados à superfície da cassiterita ou preenchendo venulações. Esta provável herança de $\mathrm{Pb}$ é comprovada pela discordância reversa exibida pelo ponto analítico da fracão $>35 \#$. Quando os pontos analíticos das fracões $>35 \#$ e 60-100\# são tratados em separado no diagrama Concórdia, fornecem idades de $2.061 \pm 38 \mathrm{Ma}$ e $2.260 \pm 17 \mathrm{Ma}$, respectivamente (Figs. $4 \mathrm{~d}$ e 4e), em regressões forçadas a intercepto inferior zero, sendo a primeira considerada mais indicativa da idade mínima do depósito dado seu
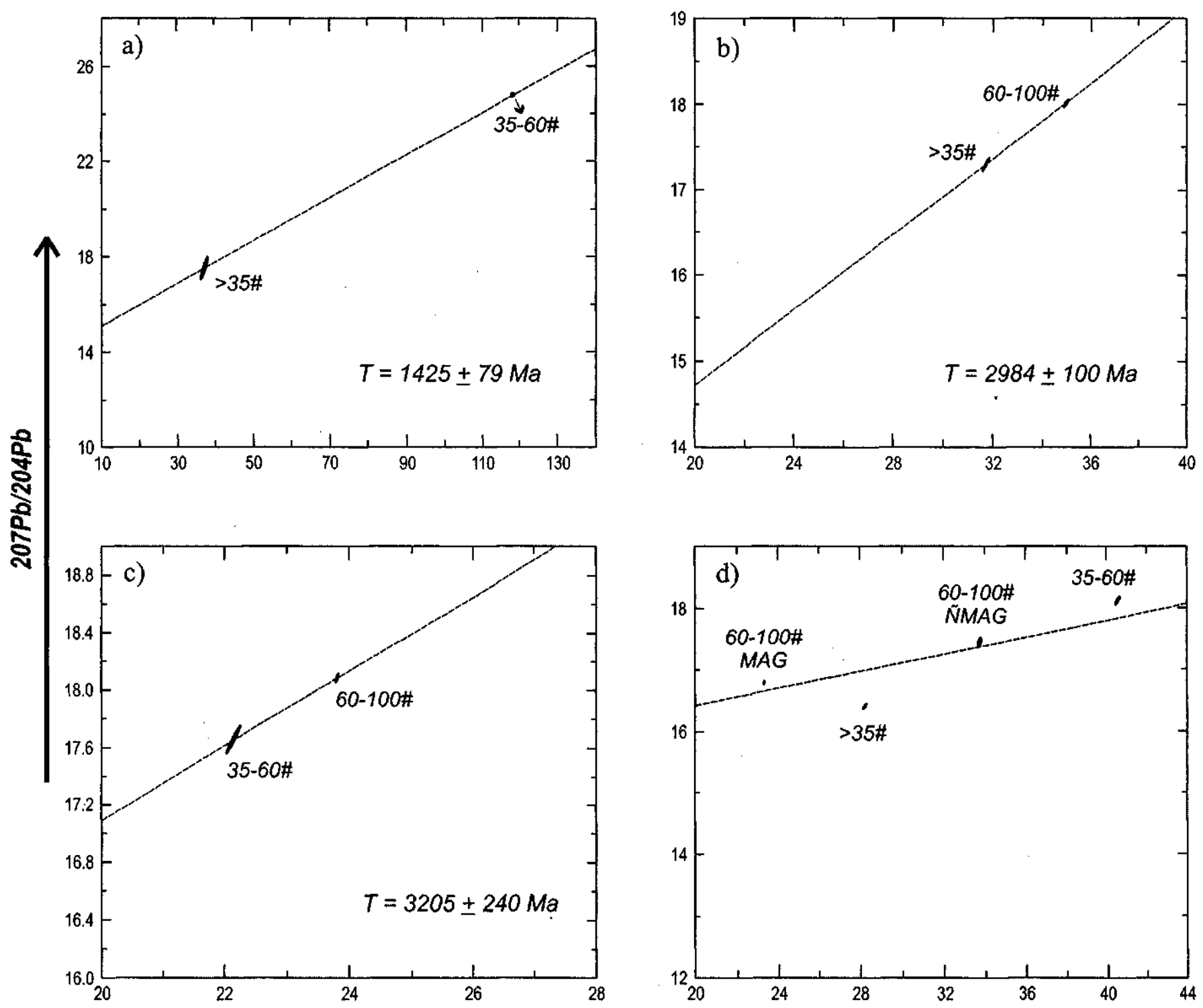

grau maior de concordância. A regressão forçada a zero é justificada pela idade K-Ar em muscovita da mesma amostra, de $2.006 \pm 24 \mathrm{Ma}$, que indica que após a formação da cassiterita não ocorreu nenhum evento geológico importante na área, que poderia provocar uma perda episódica de $\mathrm{Pb}$. A idade de 2,0 Ga também foi utilizada para a correção do conteúdo de $\mathrm{Pb}$ comum inicial segundo o modelo de Stacey \& Kramers (1975).

No Pegmatito Grotão dataram-se duas frações do concentrado de bateia denominado GROT-1 e uma de amostra de veio albítico de textura fina, chamado GROT-2. A cassiterita do Pegmatito Grotão revelou pertencer a duas gerações distintas por microscopia eletrônica de varredura, uma rica em inclusões de albita e mica branca, e outra com raras inclusões de columbita-tantalita. No caso das frações analisadas, uma delas, com concentração de $\mathrm{Pb}$ de 48,63 ppm, provavelmente concentra cristais da primeira geração citada, enquanto que as duas outras, com teores de $\mathrm{Pb}$ da ordem de $18 \mathrm{ppm}$, concentram preferencialmente cristais da geração isenta de inclusões, haja vista os teores de $\mathrm{Pb}$ em feldspato serem da ordem de 12 a 90 ppm (Oversby 1975).

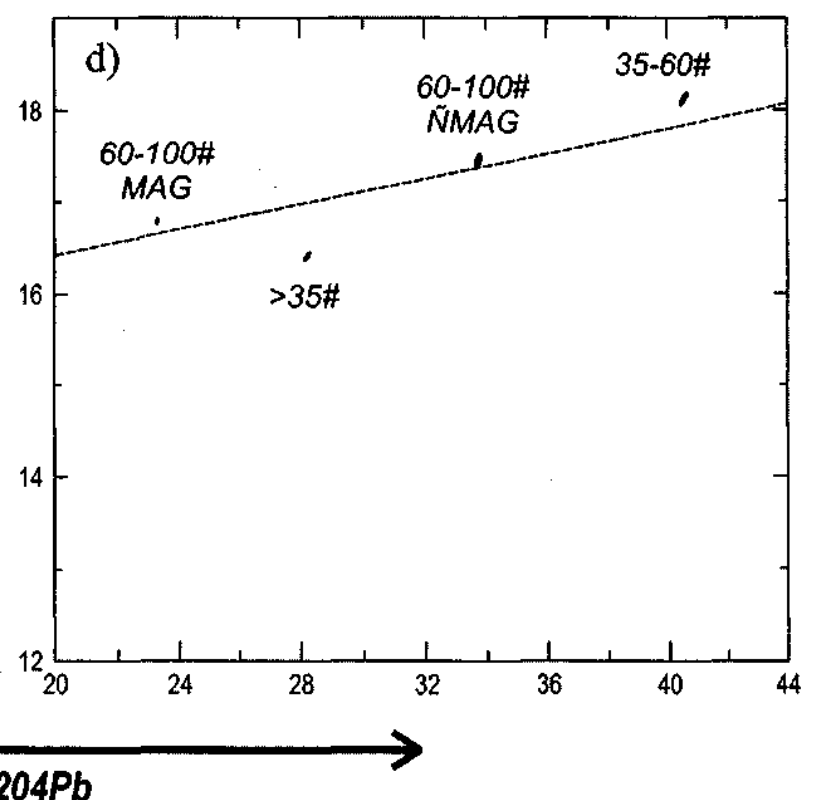

\section{$206 \mathrm{~Pb} / 204 \mathrm{~Pb}$}

Figura 5 - Diagramas isocrônicos Pb-Pb a) das/rações >35\# e 35-60\# da amostra PF-7; b) das frações >35\# e 60-100\# da amostra RC-5; c) dasfrações 35-60\# e 60-100\& da amostra XUPE-1; d) dasfrações >35\#, 35-60\# e 60-100\# magnética e não magnética da amostra INGA-2. 
Tabela 2 - Dados analiticos de Ue Pb da cassiterita da Subprovíncia do Rio Paraná (GO).

\begin{tabular}{|c|c|c|c|c|c|c|c|c|c|c|c|c|c|c|}
\hline \multirow[t]{2}{*}{ Amostra } & \multirow{2}{*}{$\begin{array}{l}\text { Peso } \\
\text { (mg) }\end{array}$} & \multicolumn{2}{|c|}{$\begin{array}{c}\text { Concentraçōes } \\
\text { (ppm) }\end{array}$} & \multicolumn{5}{|c|}{ Razōes medidas ${ }^{*}$} & \multicolumn{3}{|c|}{ Razōes atómicas ${ }^{* *}$} & \multicolumn{3}{|c|}{ Idades aparentes ${ }^{* 4}$} \\
\hline & & $u$ & $P b$ & $\frac{2000 p b}{2 \cos P b}$ & $\frac{207 P b}{204 P b}$ & $\frac{200 \mathrm{~Pb}}{200 \mathrm{~Pb}}$ & $\frac{207 P b}{206 P b}$ & $\frac{20 t p b}{206 p b}$ & $\frac{2 m p b}{3 a+U}$ & $\frac{207 P b}{2 M S U}$ & $\frac{20 \pi p b}{260 p b}$ & $\frac{200 P b}{2110}$ & $\frac{207 P b}{359 U}$ & $\frac{207 P b}{206 P b}$ \\
\hline XUPE-1 35-60: & 156,10 & 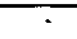 & 99,907 & 22,143 & 17,647 & 39,325 & 0,79694 & 1,7759 & $\cdot$ & $\because$ & $\because$ & 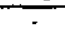 & - & - \\
\hline XUPE-1 60-100\# & 133,12 & 11,75 & 36,72 & 23,814 & 18,07 & 39,973 & 0.75878 & 1,6786 & $0,3900 \overline{8}$ & 17,7595 & 0,33020 & 2123 & $2 \overline{977}$ & 3618 \\
\hline GROT-1>35\# & 156,03 & 14,39 & 18,14 & 24,356 & 16,72 & 36,26 & $\overline{0}, 6864 \overline{9}$ & 1,4888 & $\overline{0,17130}$ & 3,92237 & $0, \overline{16606}$ & $\overline{1019}$ & $1 \overline{618}$ & 2518 \\
\hline GROT-1 35-60 & 162,18 & 13,408 & 48,633 & 23,455 & $15,9 \overline{8}$ & $\overline{36,886}$ & $\overline{0}, 6812 \overline{9}$ & $\overline{1,5726}$ & $\overline{450,44 \overline{7}}$ & 5890,99 & $0,0,0485$ & 39403 & 8815 & 1525 \\
\hline GROT-2 35-100\# & 148,54 & 10,893 & 18,708 & 23,644 & $\overline{16,16}$ & 35,034 & 0,68349 & 1,4817 & 0,22245 & 3,49707 & 0,11402 & 1295 & $1 \overline{26}$ & $18 \overline{64}$ \\
\hline$R C-5>35 \#$ & 161,53 & 3,8004 & 6,8339 & 31,690 & 17,297 & 37,752 & 0,54583 & $\overline{1,1913}$ & $\overline{0,39267}$ & 6,89737 & $0, \overline{12740}$ & 2135 & $2 \overline{098}$ & 2062 \\
\hline RC-535-60\% & $15 \overline{2}, \overline{77}$ & , & T & 33,506 & 12,701 & $\overline{37,789}$ & $\overline{0,37906}$ & $1,1278^{-1}$ & $*$ & r & . & - & - & - \\
\hline RC-5 60-100: & 91.10 & 7,1543 & 9,4556 & 34,943 & $\overline{18,014}$ & 38,493 & 0.51554 & 1,1016 & $0, \overline{3278} 1$ & 6,44882 & 0,14268 & $\overline{1828}$ & 2039 & 2260 \\
\hline INGA-2>35\# & 201,35 & 51,037 & 3,1187 & 28,218 & 16,399 & 35,492 & 0,58116 & 1,2578 & 0,01179 & 0,159647 & 0,09819 & 75 & 150 & 1590 \\
\hline INGA-2 35-66" & 198,90 & $170, \overline{37}$ & $7,50 \overline{96}$ & 40,569 & 18,119 & 39,168 & 0,44662 & 0,96548 & 0,13363 & 0,217024 & 0,14779 & 85 & 199 & 1923 \\
\hline$\overline{I N G A}-260-100^{\#} M \overline{A G}$ & 119,52 & $=$ & $\cdot$ & 23,337 & 16.778 & 46.716 & 0.71896 & 2,0018 & $=$ & $\cdot$ & $=$ & + & - & - \\
\hline INGA-2 60-100" NMAG & $20 \overline{3,50}$ & 20,681 & 8,1771 & 33,734 & 17,438 & 36,876 & 0,51693 & 1,0931 & 0,09788 & 1,67784 & 0,12432 & 602 & 1000 & 2019 \\
\hline$\overline{P F-7>35 \#}$ & 167,20 & $\cdot$ & & 37,239 & 17,493 & 36,313 & 0,46956 & 0,9752 & - & - & 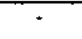 & - & $\cdot$ & $\cdot$ \\
\hline PF-7 35-60" & 97,72 & 324,76 & 115,69 & 118,20 & 24,778 & 40,267 & 0,20964 & $0,340 \overline{7}$ & 0,22949 & 2,91548 & 0,09214 & 1332 & 1386 & 1470 \\
\hline
\end{tabular}

" razó es isot́́ picas de chumbo corrigidas para branco analítico de $\mathrm{Pb}$ de $0,46 \mathrm{ng}$ (com exceção da amostra PF-7 $>35 \#$ ) e fracionamento por unidade de massa ató mica de $0,12 \%$.

" razõ es ató micas corrigidas para branco analítico de $\mathrm{Pb}$ de $0,46 \mathrm{ng}$, fracionamento por unidade de massa ató mica de $0,12 \%$, spike e $\mathrm{Pb}$ comum.

"* idades calculadas com as constantes recomendadas pela IUGS (Steiger \& Jäger 1977).

Plotadas no diagrama Concórdia, as amostras GROT-1 >35\# e

GROT-2 35-100\# não se alinharam de forma coerente (Fig. 4f). Efetuando regressões lineares forçadas a zero para cada uma em separado, obtểm-se idades mínimas de $2.518 \pm 18 \mathrm{Ma}$ e $1.854 \pm 75 \mathrm{Ma}$, respectivamente (Figs. $4 \mathrm{~g}$ e $4 \mathrm{~h}$ ). Por tratar-se de cassiterita proveniente de amostra de rocha e apresentar ponto analítico mais concordante, GROT-2 fornece aparentemente um dado mais confiável, sugerindo uma idade da ordem de 1,85 Ga para a mineralização. Neste caso, a correção de Stacey \& Kramers (1975) foi efetuada com valor arbitrado de $2.000 \mathrm{Ma}$.

O diagrama Concórdia para o depósito Xupé foi construído unicamente com a fração 60-100\#, utilizando-se a idade K-Ar da muscovita discutida na seção anterior $(2.129 \pm 26 \mathrm{Ma})$ para a correção do conteúdo de $\mathrm{Pb}$ inicial, segundo o modelo de Stacey \& Kramers (1975). O ponto analítico mostra-se altamente discordante, e a regressão da discórdia para intercepto inferior zero fornece uma idade mínima de 3.618 \pm 11 Ma (Fig. 4i). Assumindo-se a idade K-Ar da muscovita acima citada como correta para a mineralização no depósito Xupé, verifica-se que o ponto analítico da fração analisada no diagrama Concórdia está deslocado para a direita, indicando uma composição enriquecida no isótopo ${ }^{207} \mathrm{~Pb}$. Qualquer variação na abundância desse isótopo que não seja complementada por uma variação similar de ${ }^{06} \mathrm{~Pb}$ pode ser atribuída a eventos geológicos muito antigos (Faure 1986). Logo, é plausível admitir que o Pb incorporado na amostra de cassiterita tem características isotópicas de $\mathrm{Pb}$ antigo, proveniente de rochas arqueanas. Além disso, considerando-se que a composição isotópica ${ }^{206} \mathrm{~Pb} /{ }^{204} \mathrm{~Pb}$ é da ordem de $22 / 23$, portanto pouco radiogênica, podemos admitir uma presença importante de $\mathrm{Pb}$ comum proveniențe das inclusões de feldspato potássico na cassiterita da amostra XUPE-1, o que poderia influir na idade U-Pb calculada.

$\mathrm{O}$ conteúdo de $\mathrm{Pb}$ da amostra XUPÉ-1 35-60\# é quase três vezes maior do que o da fração 60-100\#, sugerindo tratarem-se de amostras de características diferentes, e indica que a fração granulométrica mais grossa concentra preferencialmente cristais da geração de cassiterita rica em mica e feldspato potássico, identificada por microscopia eletrônica de varredura.

Em relação ao depósito Ingazeira, foram analisadas três frações granulométricas da amostra INGA-2: >35\#, 35-60\# e 60-100\#, a última subdividida nas alíquotas magnética e não magnética. As con-

centrações de U dessas frações revelaram-se extremamente altas, atingindo até cerca de 170 ppm ( Tabela 2), em contraposição aos teores máximos de $\mathrm{U}$ em cassiterita de $21 \mathrm{ppm}$ relatados na literatura acima referida.

Os pontos analíticos de três frações, quando plotados no diagrama Concórdia, mostraram-se extremamente discordantes, sendo que os pontos relativos às duas frações mais grossas situam-se muito próximos ao intercepto inferior (Figs. 4j e 4k). Os pontos analíticos situamse próximos a uma reta discórdia que gera uma idade de $2.037 \mathrm{Ma}$ com erro elevado de 1.634 Ma e MSWD = 17. Agrupando-se a cada dois pontos, obtêm-se idades de $2.056 \pm 49$ Ma $(>35 \#$ com $60-100 \#$ não magnética) e $2.030 \pm 49 \mathrm{Ma}$ (35-60\# com 60-100\# não magnética), que poderiam ser significativas da idade de formação da cassiterita analisada. Os valores dos interceptos inferiores, em ambos os casos, são desprovidos de significação geológica, e podem ser atribuídos a aporte de U em evento recente, provavelmente de natureza intempérica, o que explicaria os teores anómalos deste elemento na cassiterita. Para a correção do conteúdo de $\mathrm{Pb}$ comum inicial segundo Stacey \& Kramers (1975), utilizou-se o valor de $2.218 \mathrm{Ma}$, obtido em diagrama isocrônico $\mathrm{Pb}-\mathrm{Pb}$ em cassiterita, que será discutido adiante.

Apesar de existirem apenas duas análises $\mathrm{Pb}-\mathrm{Pb}$ em cassiterita bem sucedidas para cada deposito estudado, o que sem dúvida prejudica a interpretação dos resultados obtidos, algumas ilações a respeito dos dados podem ser feitas.

No diagrama isocrônico $\mathrm{Pb}-\mathrm{Pb}$ da figura $5 \mathrm{a}$, construído para a cassiterita do Granito Mangabeira ( amostra PF-7), as duas amostras analisadas forneceram uma idade de $1.425 \pm 79$ Ma que concorda, dentro dos erros analíticos, com as idades fornecidas pelo método U-Pb para a mesma amostra.

Os diagramas isocrônicos $\mathrm{Pb}-\mathrm{Pb}$ para a cassiterita dos depósitos Riacho dos Cavalos (RC-5) (Fig. Sb) e Xupé (XUPE-1) (Fig. Sc) forneceram dados da ordem de 3.000 Ma que, embora não possam ser considerados como a idade verdadeira da cassiterita, indicam a natureza antiga do $\mathrm{Pb}$ presente na mesma, predominantemente na forma de inclusões e fases minerais tardias.

No Pegmatito Grotão, não foi possível obter-se uma idade isocrônica $\mathrm{Pb}-\mathrm{Pb}$ em função da inexistência de variação na composição isotópica de $\mathrm{Pb}$ das frações analisadas. 
No depósito Ingazeira, os quatro pontos analíticos disponíveis não são colineares, quando lançados em diagrama isocrônico $\mathrm{Pb}-\mathrm{Pb}$ (Fig. 5d). Mesmo considerando-se os três pontos melhor alinhados, o dado obtido revela erro maior que a cifra da própria idade. Excluídos, então, os dois pontos relativos à fração $60-100 \#$, obtém-se a idade de $2.218 \pm 50 \mathrm{Ma}$. Alternativamente, se plotados apenas os pontos analíticos das alíquotas magnética e não magnética da fração 60-100\#, a idade obtida é de $724 \pm 210 \mathrm{Ma}$, o que leva a concluir que a cassiterita analisada não estava homogeneizada isotopicamente e que a última fração (60-100\#) teve o seu sistema U-Pb parcialmente aberto em algum evento geológico posterior, possivelmente relacionado às texturas cataclásticas exibidas pela fase mineral, em função da granulação fina. Considerando-se que foram obtidas idades $\mathrm{U}-\mathrm{Pb}$ da ordem de 2,0 Ga para esta mineralização, o valor de $2.218 \mathrm{Ma}$, é mais próximo da idade real de formação da cassiterita.

Tais dados, de caráter preliminar, contradizem o modelo genético assumido para o depósito da Ingazeira, situado próximo ao contato oeste entre o Granito Mocambo e o Complexo Grànito-Gnáissico, e classificado por Botelho et al. (1986) como exogreisen de fratura.

CONCLUSÕES A datação U-Pb de minerais de minério, como a cassiterita, é de aplicação difícil, principalmente em função da possibilidade de herança de $\mathrm{Pb}$ comum e de evolução isotópica complexa do $\mathrm{Pb}$ na crosta continental. Dos diversos depósitos datados por U-Pb em cassiterita neste trabalho, aqueles relacionados a granitóides parecem ser mais adequados para análises isotópicas, em virtude de apresentarem cassiterita com alto teor de U. A cassiterita associada aos pegmatitos analisados apresentou fatores complicadores à aplicação dessa sistemática, na medida em que possui inclusões ou fases minerais tardias que incorporam $\mathrm{Pb}$ comum precipitadas em fraturas. Ganho significativo de U pela cassiterita também pôde ser constatado no caso do depósito Ingazeira. Todavia, pontos analíticos pouco discordantes são gerados no caso da análise de cassiterita isenta de inclusões ou de fases minerais tardias, e as idades resultantes concordam com dados conhecidos por outros métodos e da literatura para as mesmas rochas.

A análise de frações granulométricas distintas revelou-se ineficiente, não havendo diferença significativa nas composições isotópicas de $\mathrm{Pb}$. A separacão magnética, entretanto, produziu variação sensível da composição isotópica no único caso estudado, corroborando o parecer de Gulson \& Jones (1992) a respeito da aplicação dessa técnica.

Diagramas isocrônicos $\mathrm{Pb}-\mathrm{Pb}$ demonstram a evolução em multiestágios do $\mathrm{Pb}$ incorporado nas inclusões de feldspato e na própria cassiterita dos pegmatitos de Monte Alegre, sugerindo a existência de um embasamento antigo retrabalhado naquela área, o que não foi constatado nos demais depósitos. Datações K-Ar em muscovita revelam que a referida área trata-se de um domínio não afetado pelas deformacões brasilianas que perturbaram os granitóides estaníferos localizados no centro-oeste da Subprovíncia, e implicam em admitir uma idade mínima de 2.150 Ma para o Complexo Grànito-Gnáissico e a Formação Ticunzal.

No depósito da Ingazeira, situado no contato oeste do Granito Mocambo, os dados geocronológicos conduzem a uma origem contemporânea à dos pegmatitos, durante o Ciclo Transamazônico.

Pelo presente trabalho, com base em datações K-Ar em muscovita e U-Pb em cassiterita, identificaram-se dois eventos de mineralizacão estanífera na Subprovíncia do Rio Paraná. O mais antigo, de idade transamazônica, está representado pelos pegmatitos intrusivos no Complexo Grànito-Gnáissico e na Formacão Ticunzal, localizados a nordeste da cidade de Monte Alegre de Goiás. O mais jovem, com idades entre $1.535 \mathrm{Ma}$ e $1.470 \mathrm{Ma}$, que é amplamente estudado na literatura, relaciona-se aos granitos mesoproterozóicos da família magmática g2 (sensu Botelho 1992a, b).

A caracterização mineral da cassiterita por microscopia eletrônica de varredura levou à identificação de duas gerações do mineral em função da natureza das inclusões que ocorrem na fase, principalmente nos depósitos Xupé e Grotão: uma com inclusões predominantemente feldspáticas, com contribuição de mica branca e quartzo, e outra com inclusões de minerais do grupo da columbita-tantalita.

Agradecimentos À Salomão Mineração Ltda., nas pessoas do geólogo Gilmar de Assis Pagotto e dos funcionários Lourival de Jesus Maciel e Hélio dos Remédios dos Santos, ao corpo técnico do Centro de Pesquisas Geocronológicas (CPGeo) do Instituto de Geociências, Universidade de São Paulo, aos pesquisadores do Laboratório de Caracterização Tecnológica do Departamento de Engenharia de Minas da Escola Politécnica, Universidade de São Paulo, e ao Dr. Márcio Martins Pimentel do Laboratório de Geqcronologia do Instituto de Geociências, Universidade de Brasília. A valiosa colaboração dos Professores Doutores Jorge Silva Bettencourt, Marly Babinski e Miguel Stipp Basei do Instituto de Geociências da Universidade de São Paulo, ao Mestre Tarcísio José Montanheiro, geólogo do Instituto Geológico de São Paulo, e ao Professor Nilson Pinto Teixeira, da Universidade Federal do Pará. A FAPESP (Projeto Temático n! 95/4652-2), pelo auxílio financeiro para os trabalhos analíticos, e à Capes, pela bolsa de Mestrado concedida ao primeiro autor. A dois revisores anónimos da RBG pelas sugestões ao texto original.

\section{Referências}

Babinski, M. 1993. Idades isocrônicas $\mathrm{Pb} / \mathrm{Pb}$ e geoquímica isotópica de $\mathrm{Pb}$ das rochas carbonáticas do Grupo Bambuí, na porção sul da Bacia do São Francisco. Inst. de Geociências, Universidade de São Paulo, São Paulo, Tese de Doutoramento, 133 p.

Bell, K.; Anglin, C.D.; Franklin, J.M. 1989. Sm-Nd and Rb-Sr isotope systematics of scheelites: Possible implications for the age and génesis of vein-hosted gold deposits. Geology, 17(6):500-504

Berzina, I.G. \& Dolomanova, Ye. L. 1967. Uranium content of cassiterite, as determined by tracks left by fission fragments of uranium. Doklady ofthe Academy of Sciences U.S.S.R., Earth Science Sections, 175(1-6): 114-118

Bjorlykke, A.; Cumming, G.L.; Krstic, D. 1990. New Isotopic Data from Davidites and Sulfides in the Bidjovagge Gold-Copper Deposit, Finnmark, Northern Norway. Mineralogy and Petrology, 43(1):1-21

Botelho, N.F. 1997. Granites and related ore deposits in Central Brazil. In: SBG, International Symposium on Granites and Associated Mineralizations, 2, Salvador, Extended Abstract and Program, p. 36-37.

Botelho, N.F. 1992a. Lês ensembles granitiques subalcalins à peralumineux mineralisés en Sn et In de Ia Sous-Province Paraná, Etat de Goiás, Brésil. Université Paris VI, Paris, Tese de Doutoramento, $344 \mathrm{p}$.

Botelho, N.F. 1992b. Caracterização de duas famílias de granitos subalcalinos a peraluminosos na Subprovíncia Estanífera do Paranã: consequências sobre a geologia, a petrologia e a metalogenia dos granitos estaníferos de Goiás. In: SBG, Congresso Brasileiro de Geologia, 37, São Paulo, Boletim de Resumos Expandidos,. p. 360-361.

Botelho, N.F.; Marini, O.J.; Pagotto, G.; Rossi, G.; Abe, C.K.; Ura, C.; Postal, F. 1986 Província estanífera do leste de Goiás (Subprovíncia do Rio Paranã). In: SBG, Congresso Brasileiro de Geologia, 34, Goiânia, Boletim n²-Roteiro das excursões técnico-cientificas, p. 133-147.

Corfu, F. \& Andrews, A.J. 1986. A U-Pb age/ormineralized Nipissing diabase, Gowganda, Ontario. Canadian Journal of Earth Sciences, 23:107-109.

Corfu, F. \& Muir, T.L. 1989. The Hemlo-Heron Bay greenstone belt and Hemlo Au-Mo deposit, Superior Province, Ontario, Canada. Chemical Geology, 79:201-223.

Darbyshire, D.P.F.; Pitfield, P.E.J.; Campbell, S.D.G. 1996. Late Archean and Early Proterozoic gold-tungsten mineralization in the Zimbabwe Archean craton: $\mathrm{Rb}-\mathrm{Sr}$ and Sm-Nd isotope constraints. Geology, 24(1):19-22.

Dyer, R.C. 1970. Grupo Arai -um grupo de metamorfitos do centro leste de Goiás. Revista da Escola de Minas, 28(2):55-63.
Faure, G. 1986. Principies of Isotope Geology. 2 ed. New York, John Wiley \& Sons, 589 $\mathrm{P}-$

Fernandes, P.E.C.A.; Montes, M.L.; Braz, E.R.C.; Montes, A.S.L.; Silva, L.L.; Oliveira, F.L.L.; Ghignone, J.I.; Siga JR., O.; Castro, H.E.F. 1982. Folha SD.23 Brasilia geologia. Rio de Janeiro, MME, p. 25-204. (Série Projeto RADAMBRASIL).

Frei, R. \& Petkke, T. 1996. Mono-sample $\mathrm{Pb}-\mathrm{Pb}$ dating of pyrrhotite and tourmaline: Proterozoic vs. Archean intracratonic gold mineralization in Zimbabwe. Geology, 24(9):823-826.

Fuck, R.A.; Pimentel, M.M.; Botelho, N.F. 1987. Granitoid rocks in west-central Brazil: a review. In:SGM, SME, International Symposium on Granites and Associated Mineralizations, 1, Salvador, Extended abstracts, p. 53-59.

Gulson, B.L. \& Jones, M.T. 1992. Cassiterite: Potential fordirect dating of mineral deposits and a precise age for the Bushveld Complex granires. Geology, 20(4):355-358.

Hanes, J.A. 1991. K-Ar and ${ }^{40} \mathrm{Ar} /{ }^{39}$ geochronology: methods and applications. In: L. Heaman \& J.N. LUDDEN (eds) Applications of Radiogenic Isotope Systems to Problems in Geology. Toronto, Mineralogical Association of Canada,. 27-57. (Short Course Handbook, 19).

Hasui, Y.; Tassinari, C.C.G.; Siga JR., O.; Teixeira, W.; Almeida, F.F.M. de; Kawashita, K. 1980. Datações Rb-Sr e K-Ar do centro-norte do Brasil e seu significado geológico-geotectônico. In: SBG, Congresso Brasileiro de Geologia, 31, Balneário de Camboriú, Anais,. 5:2659-2676.

Ludwig, K.R. 1993. ISOPLOT - A Plotting and Regression Program for Radiogenic-Isotope Data, Version 2.70. June 9, 1993 revision of U.S. Geological Survey Open File Report $91-445,42 \mathrm{p}$.

Ludwig, K.R. 1993. PBD AT -A Computer Program for Processing Pb-U-Th Isotope Data Version 1.24. June 22,1993 revision of U.S. Geological Survey Open File Report $88-542,34 \mathrm{p}$.

Ludwig, K.R. \& Cooper, J. A. 1984. Geochronology of Precambrian granites and associated U-Ti-Th mineralization, northern Olary province, South Austrália. Contributions to Mineralogy and Petrology, 86:298-308.

Marini, O.J. \& Botelho, N.F. 1986. A província de granitos estaníferos de Goiás. Revista Brasileira de Geociências, 16(1): 119-131.

Marini, O.J.; Botelho, N.F.; Macambira, M.J.B.; Provost, A. 1985. Idade do Granito Pedra Branca (Goiás) e possíveis implicações geotectônicas. In: SBG, Simpósio de Geologia do Centro-Oeste, 2, Goiânia, Ata, p. 90-105. 
Marini, O.J.; Fuck, R.A.; Dardenne, M.A.; Danni, J.C.M. 1984. Província Tocantins -setores Central e Sudeste. In: F.F.M. Almeida, \& Y. Hasui (coords) $O$ Pré-Cambricmo do Brasil. São Paulo, Edgard Blücher, 205-264.

Marini, O.J.; Liberal, G.S.; Reis, L.T.; Trindade, C.A.; Souza, S.L. 1978. Nova unidade litoestratigráfica do Pré-Cambriano do estado de Goiás. In: SBG, Congresso Brasileiro de Geologia, 30, Recife,Bo/eri/n 7 - Resumo das Comunicações, $\mathrm{p}$. 126-127.

Mezger, K.; Hanson, G.N.; Bohlen, S.R. 1989. High-precision U-Pb ages of metamorphic rutile: application to the cooling history of high-grade terranes. Earth andPlanetary Science Letters, 96:106-118.

Montanheiro, T.J. 1994. Estudo comparativo de amostragem em furos de sondagem e galerias para pesquisa de cassiterita no Pegmatito Xupé -Monte Alegre de Goiás, $G O$. Inst. de Geociências, Universidade de São Paulo, São Paulo, Dissertação de Mestrado, $122 \mathrm{p}$

Oversby, V.M. 1975. Lead isotopic systematics and ages of Archaean acid intrusives in the Kalgoorlie-Norseman área, Western Austrália. Geochimica et Cosmochimica Acta, 39(8):1107-1125.

Pimentel, M.M.; Heaman, L.; Fuck, A.R.; Marini, O.J. 1991. U-Pb zircon geochronology of Precambrian tin-bearing continental-type acid magmatism in central Brazil. Precambrian Research, 52(3/4):321-335.

Reis Neto, J.M. 1983. Evolução Geotectônica da Bacia do Alto Tocantins, Goiás. Inst. de Geociências, Universidade de São Paulo, São Paulo, Dissertação de Mestrado, 98

Richards, J.P.; Krogh, T.E.; Spooner, E.T.C. (1988) Fluid Inclusion Characterisitícs and U-Pb Rutile Age of Late Hydrothermal Alteration and Veining at the Musoshi Stratiform Copper Deposit, Central African Copper Belt, Zaire. Economic Geology, 83:118-139.

Romer, R.L. \& Lehmann, B. (1995) U-Pb Columbite Age of Neoproterozoic Ta-Nb Mineralization in Burundi. Economic Geology, 90:2303-2309.

Romer, R.L. \& Smeds, S-A. 1997. U-Pb comulbite chronology of post kinematic Palaeoproterozoic pegmatites in Sweden. Precambrian Research, 82:85-99.

Romer, R.L. \& Smeds, S-A. 1994. Implications of U-Pb ages of columbite-tantalites form granitic pegmatites for the Palaeoproterozoic accretion of 1.90-1.85 Ga magmatic ares to the Baltic Shield. Precambrian Research, 67:141-158.
Romer, R.L. \& Wright, J.E, 1992. U-Pb dating of columbites: A geochronologic tool to date magmatism and ore deposits. Geochimica et Cosmochimica Acta, 56:2137-2142

Schandl, E.S.; Davis, D.W.; Krogh, T.E. 1990. Are the alteration halos of massive sulfide deposits syngenetic? Evidence from U-Pb dating of hydrothermal rutile at the Kidd volcanic center, Abitibi subprovince, Canada. Geology 18:505-508.

Schárer, U.; Krogh, T.E.; Gower, C.F. 1986. Age and evolution of the Grenville Province in eastern Labrador from U-Pb systematics in accessory minerais. Contributions to Mineralogy and Petrology, 94:438-451.

Sparrenberger, 1.1998. A cassiterita da Subprovincia do Rio Paraná (GO): dotações U-Pb $e P b-P b$ e caracterização mineral. Inst. de Geociências, Universidade de São Paulo, São Paulo, Dissertação de Mestrado, 136 p.

Stacey, J.S. \& Kramers, J.D. 1975. Approximation of terrestrial lead isotope evolution by a two-stage model. Earth and Planettary Science Letters, 26:207-221.

Steiger, R.H. \& Jàger, E. 1977. Subcommission on geochronology: Convention on the use of decay constants in geo- and cosmochronology. Earth and Planettary Science Letters, 36:359-362.

Swart, P.K. \& Moore, F. 1982. The occurrence of uranium in associaüon with cassiterite, wolframite, and sulphide mineralization in South-West England. Mineralogical Magazine, 46(339):211-215.

Tassinari, C.C.G.; Siga JR., O.; Teixeira, W. 1981. Panorama geocronológico do centro-oeste brasileiro: soluções problemáticas e sugestões. In: SBG, Simpósio de Geologia do Centro-Oeste, 1, Goiânia, Ata, p. 93-114.

Torquato, J.R. \& Kawashita, K. 1992. O método K/Ar. Revista de Geologia, 5:177-207.

Turpin, L:; Maruejol, P.; Cuney, M. 1988. U-Pb, Rb-Sr and Sm-Nd chronology of granitic basement, hydrothermal albitites and uranium mineralization (Lagoa Real, South-Bahia, Brazil). Contributions to Mineralogy and Petrology, 98:139-147.

Zagruzina, I.A.; Pinskii, E.M.; Savinova, I.B. 1987. Uranium in cassiterite of tin deposits. International Geology Review, 29(1):94-109.

Manuscrito A-1070

Recebido em 20 de janeiro de 1999

Revisão dos autores em 17 de maio de 1999 Revisão aceita em 20 de maio de 1999 